\title{
Norbert Elias. O Processo Civilizador: Uma História dos Costumes
}

Jefferson Alexandre da Silva

\section{Resumo:}

A resenha apresenta de forma sintética as questões tratadas no primeiro volume de O Processo civilizador de Norbert Elias, porém, chama a atenção para o que há de essencial na argumentação de Norbert Elias, a saber: que o processo civilizador pode ser entendido como um processo de transformação de longo prazo nas estruturas de personalidade e comportamentos individuais.

Palavras-chave: Norbert Elias, O Processo civilizador, sociologia. 
É indiscutível, dentro das discussões da sociologia contemporânea, a importância das contribuições de Norbert Elias (I897-I990). Mesmo que o seu reconhecimento em vida tenha sido posterior à elaboração da presente obra, com a publicação de Sociedade de Corte (Die höfische Gesellschaft) em I969. Se, por um lado, O Processo civilizador se constitui como uma obra marcada cronológica e espacialmente, isto é, inserida no desenvolvimento histórico e científico específicos da Europa e, mais precisamente do alemão. Por outro lado, estamos diante de um trabalho sociológico que transcende o período de sua produção.

O contexto intelectual e científico no qual Elias produziu a presente obra estava impregnado das discussões acerca da eugenia e, consequentemente, dos conceitos de civilização e barbárie. Os estudos desenvolvidos por Francis Galton (I822-I9II) e Alfred Ploetz (I860-I940) acerca da superioridade racial de algumas "espécies humanas" em detrimento de outras, ou seja, a existência de uma raça possuidora de certas características definidoras do "homem civilizado", em contraposição a uma raça inferior caracterizada pela barbárie, estavam disseminados na ciência experimental européia.

Por outro lado, a publicação das obras de Sigmund Freud (I856-I939) e as suas descobertas no âmbito da psicanálise, influenciaram boa parte da sociologia da década de I930-I940, em especial a presente obra de Norbert Elias. A grande influência de Freud em $O$ Processo civilizador se deve a descoberta do superego e da consciência e, principalmente, ao caráter social da formação psicológica do indivíduo.

Além das teorias científicas desenvolvidas nessa época, o contexto histórico também marca diretamente essa obra. A eclosão da Grande Guerra em I9I4 e seu término em I9I8 é um fator que marca a ruptura da "evolução" histórica européia - a civilização da belle époque - para a decadência e a barbárie. Norbert Elias cita alguns "retrocessos" no comportamento civilizado ocasionados pela guerra (ELIAS, I994, pp.I89-202). Na Alemanha, a ascensão do nazismo em I933 e a aplicação da lei racial alemã de 1937 têm um grande peso na elaboração da obra de Norbert Elias, pois tais acontecimentos interferiam diretamente em sua vida: um judeu - raça considerada inferior pela lei de I937 - alemão que vive na Alemanha nazista e que decide publicar trabalhos acerca da civilização.

Seria OProcessocivilizadorumarespostaaosacontecimentoscontemporâneos de Elias? A resposta a questão não pode ser dada com precisão, mas a forma como o autor elabora sua pesquisa e as conclusões as quais ele chega podem ser consideradas uma crítica a noção de naturalidade do comportamento e maneiras das nações ditas civilizadas, afinal, o processo civilizador, diz Elias, é o resultado último de um desenvolvimento histórico cuja característica é o "refinamento" das ações e a introspecção dessas pelo indivíduo (ELIAS, I994, p.48;73;I89). 
O Processo civilizador é publicado em I939 na Suíça e o primeiro volume está dividido em dois capítulos principais: o primeiro é intitulado " $\mathrm{Da}$ sociogênese dos conceitos de 'civilização' e 'cultura'" e o segundo capítulo discute "A civilização como transformação do comportamento humano".

No primeiro capítulo, Elias discute os conceitos de Kultur e Zivilisation no desenvolvimento das relações sociais na Alemanha e França, desde o século XVI ao presente. Para os alemães, segundo Elias, o termo civilização é um conceito de segunda categoria, uma vez que não alude a características intelectuais do povo alemão, e sim a comportamentos e atitudes, como é o caso francês no desenvolvimento do mesmo conceito:

O que se manifesta nesse conceito de Kultur, na antítese entre profundeza e superficialidade, e em muitos conceitos correlatos é, acima de tudo, a autoimagem do estrato intelectual de classe média [...] o que fornece os alicerces à sua autoimagem e orgulho, situa-se além da economia e da política. Reside [...] no chamado das rein Geistige (puramente espiritual) (ELIAS, I994, p.43).

Conforme expõe Elias, o conceito de Kultur teve sua origem na classe média alemã, uma vez que a aristocracia cortesã da Alemanha estava culturalmente muito mais próxima da aristocracia francesa (falavam e liam em francês, sua etiqueta e rituais cortesãos eram inspirados na corte francesa de Luís XIV) do que da cultura alemã. É por meio das universidades, dominadas pela classe média, e as influências das obras de Goethe e Kant que "redescobrem" o alemão como língua produtora de literatura, disseminam, principalmente após o processo de unificação, tais características culturais para toda a sociedade alemã.

Por outro lado, civilização é a expressão da "autoimagem da classe alta européia em comparação com outros, que seus membros consideravam mais simples ou mais primitivos [...]" (ELIAS, I994, p.54). Sendo assim, o conceito de civilização é a forma como a alta classe européia entende o desenvolvimento da sua própria história e, também, uma forma de se entender todo o desenrolar histórico dos outros povos, sempre estabelecendo uma relação de distanciamento entre o "nós"= "civilizados" e o "eles"= "bárbaros". Assim, as nações que se denominam civilizadas acreditam estar no ápice do desenvolvimento da humanidade, o que lhes dá o direito de subjugar aqueles que são anteriores à civilização (ELIAS, I994, p.64). Contudo, esse mesmo conceito que engrandece as nações civilizadas relaciona-se intrinsecamente a sua antítese a noção de decadência ou degeneração, perigo constante para a civilização. A civilização está constantemente ameaçada pelo processo de degeneração, sendo necessárias reformas que evitem a 
decadência da sociedade civilizada.

As nações civilizadas compreendem que sua condição de ápice civilizatório é uma condição a-histórica, isto é, os comportamentos e as maneiras "civilizadas" sempre foram constantes. Interessante observar como Elias procura destruir essa noção que na década de 1930, era tida como consenso, demonstrando que o "refinamento" das maneiras e comportamentos foram resultados de vários processos graduais de transformações estruturais no comportamento, mentalidade, emoções e, finalmente, da personalidade dos indivíduos que se consideram civilizados. Tal é o empreendimento da segunda parte do volume.

A tese de Norbert Elias acerca do processo civilizador expressa que:

A "civilização" que estamos acostumados a considerar como uma posse que aparentemente nos chega pronta e acabada, sem que perguntemos como viemos a possuir-la, é um processo ou parte de um processo em que nós mesmos estamos envolvidos. Todas as características distintivas que lhe atribuímos - a existência de maquinaria, descobertas científicas, formas de Estado, ou o que quer que seja - atestam a existência de uma estrutura particular de relações humanas, de uma estrutura social particular, e de correspondentes formas de comportamento (ELIAS, I994, p.73).

De modo a sustentar tal tese, Elias aplica a metodologia de análises de processos de longa duração com resultados não previstos pelos agentes da ação inicial. Na prática, Elias trabalha com documentação histórica referente a instituição de regras e padrões quanto a determinados comportamentos.

Dessa forma, o autor perpassa por diversos períodos históricos discutindo como se dá o refinamento das ações diante dos outros indivíduos e a transposição de ações consideradas vergonhosas e nojentas apenas para o plano privado da vida individual. Essa introspecção de determinadas ações é o resultado da coação entre os indivíduos, advinda de uma maior observação, pelas outras pessoas, de como se porta o outro (ELIAS, I994, p. 9I). Longe de ser um desenvolvimento racional (ELIAS, I994, p. 2I4), o processo civilizador se constitui como o aumento do sentimento de vergonha sobre determinados comportamentos, resultando em uma modificação na estrutura mental e emocional. $O$ resultado final desse processo é o desenvolvimento de um autocontrole de suas ações e emoções e uma transformação na estrutura da personalidade dos indivíduos.

A síntese desse trabalho de Norbert Elias poderia ser caracterizada pela evolução conceitual de determinados tipos de estruturas desenvolvidos pelo autor: comportamento, mental e emocional e, finalmente, de personalidade. O tratamento que o autor dá a esses conceitos decorre, juntamente, com o 
aprofundamento e a interiorização do processo civilizador, passando dos estágios mais superficiais desse processo (estrutura de comportamento) à instâncias humanas mais profundas (estrutura de comportamento).

A criação de uma nova estrutura de comportamento decorre de um longo processo no qual o indivíduo, através de coação externa, internaliza todas as maneiras e os comportamentos considerados "civilizados", passando a fazer parte da própria constituição do ser, que adota determinados comportamentos inconscientemente (ELIAS, I994, p. I89). Assim, o processo civilizador sai da superfície "uniformemente de uma maneira específica que transcende as diferenças individuais" (ELIAS, I994, p. 48) - estruturas de comportamento -, inserindose em instâncias mais profundas do ser, como as estruturas, mental e emocional, e quando está profundamente constituído no indivíduo e, mais genericamente, na coletividade, desenvolve-se uma modificação na estrutura de personalidade. $O$ processo civilizador internaliza comportamentos sociais nos indivíduos, através de ações coercitivas, estabelecendo modificações profundas no mesmo, o qual concebe suas atitudes, emoções e personalidade como algo natural e constituinte do indivíduo, fazendo-o perder a consciência de que sua constituição psíquica e emocional fazem parte de um longo processo de transformações nas relações sociais no percurso da história.

O Processo civilizador é uma obra que está inserida no contexto social e intelectual europeu da década de I930. No entanto, o seu desenvolvimento teórico e a aplicação metodológica realizada por seu autor apreendem conceitos que são caros as ciências sociais contemporâneas. Cientistas sociais posteriores desenvolviam questões teóricas semelhantes às de Elias, como o conceito de autodisciplina de Foucault, elucidado em sua clássica publicação em Survelleir et Punir: Naissance de la prision (1975) que, em uma certa medida, assemelhase com o desenvolvimento conceitual do autocontrole eliasiano. Além disso, a metodologia de analisar figurações sociais de longa duração, estabelecendo relações estruturais remete às noções que estavam sendo desenvolvidas por Fernand Braudel acerca dos processos históricos de longa duração.

Longe de afirmar que os conceitos eliasianos de autocontrole e longa duração sejam a origem dos conceitos foucaultnianos ou braudelianos, respectivamente, mas a comparação é válida e demonstra a importância teórica de Norbert Elias o que justifica a constituição de O Processo civilizador como uma obra clássica da sociologia contemporânea. 


\section{Referências Bibliográficas:}

ELIAS, Norbert. O Processo civilizador: Uma história dos costumes, trad. Ruy Jungmann, revisão e apresentação Renato J. Ribeiro, Rio de Janeiro: Jorge Zahar Ed., I994; traduzido de Über den Prozess der Zivilisation vol.I, publicado originalmente em I939 na Basiléia, Suíça.

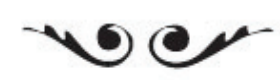

Jefferson Alexandre da Silva é graduando em Ciências Sociais pela USP.

E-mail: alexandre.jeffersonI@gmail.com 